Revista Aspas

ppgac - USP

\title{
Desenhos de Pesquisa
}

\section{O CENTRO POPULAR DE CULTURA \\ DE SANTO ANDRÉ E SUA PROPOSTA DE UM TEATRO PROLETÁRIO}

THE POPULAR CENTER OF CULTURE OF SANTO ANDRÉ AND ITS PROPOSAL OF A PROLETARIAN THEATER

EL CENTRO POPULAR DE CULTURA DE SANTO ANDRÉ Y SU PROPUESTA DE UN TEATRO PROLETARIO

\section{Jacqueline da Silva Takara}

Jacqueline da Silva Takara

Mestranda em Teoria e prática do Teatro na Escola de Comunicações e Artes da Universidade de São Paulo (ECA/USP). 


\section{Resumo}

A pesquisa sobre o Centro Popular de Cultura (CPC) de Santo André tem o objetivo de resgatar sua história por meio de suas principais fontes teóricas e documentais, publicadas sobretudo no final dos anos de 1990, além de entrevistas e periódicos como o News Seller e o Diário do Grande $A B C$. Além disso, pretende-se investigar suas proposições estéticas e políticas, comparando-as com a experiência do CPC da União Nacional dos Estudantes (UNE) e suas críticas posteriores.

Palavras-chave: União nacional dos estudantes, Teatro de arena, Sociedade de cultura artística de Santo André, Partido comunista brasileiro.

\section{Abstract}

The research on the Popular Center of Culture (CPC) of Santo André has the objective of recovering its history through its main theoretical and documentary sources, published mainly in the late 1990s, besides interviews and newspapers such as the News Seller and the Diário do Grande $A B C$. Furthermore, this study intends to investigate its aesthetic and political propositions, comparing them with the experience of the CPC of the National Union of Students (UNE- União Nacional dos Estudantes) and its later criticisms.

Keywords: National union of students, Teatro de Arena, Society of artistic culture of Santo André, Brazilian communist party.

\section{Resumen}

La investigación sobre el Centro Popular de Cultura (CPC) de Santo André tiene el objetivo de rescatar su historia por medio de sus principales fuentes teóricas y documentales, publicadas sobre todo al fin de los años 1990, además de entrevistas y periódicos como el News Seller y el Diário do Grande ABC. Además, se pretende investigar las proposiciones estéticas y políticas, comparándolas con la experiencia del CPC de la UNE (Unión Nacional de los Estudiantes) y sus críticas posteriores.

Palabras clave: Unión nacional de los estudiantes, Teatro de arena, Sociedad de cultura artística de Santo André, Partido comunista brasileño. 
O Centro Popular de Cultura da União Nacional dos Estudantes da (CPC-UNE) durou de 1961 a 1964 e teve como cerne político as lutas anti-imperialistas e nacional-desenvolvimentistas impulsionadas sobretudo por meio de atividades artísticas, cujas proposições estéticas se vinculavam a ideia de cultura popular.

O CPC nasce a partir da montagem da peça teatral $A$ mais-valia vai acabar, seu Edgar, feita no antigo Estado da Guanabara, no vão da Faculdade Nacional de Arquitetura, encenada pelo Grupo Jovem, com a direção de Oduvaldo Vianna Filho (Vianinha), direção de Chico de Assis e composições musicais de Carlos Lyra.

A peça recebe as orientações teóricas de Carlos Estevam Martins, que havia iniciado sua carreira como sociólogo no Instituto Superior de Estudos Brasileiros (Iseb), e é uma tentativa de elucidar o público sobre o conceito marxista que escancara a exploração dos trabalhadores pelos capitalistas.

Segundo Chico de Assis, em sua "pior" fase, chegou a uma média de 400 pessoas em cada sessão, sendo apresentada durante oito meses (CAMARGO, 1996, p. 75). Sua estreia ocorre no dia 28 de julho de 1960 e, segundo a nota introdutória da obra Peças do CPC - A mais-valia vai acabar seu Edgar e mundo enterrado, a peça "se torna motivo de ferrenha crítica tanto de militantes de esquerda, que viam pouco rigor conceitual e revolucionário no texto, como pelo lado dos artistas que condenavam na obra a instrumentalização política da arte" (MAYOR et al., 2016, p. 10).

A montagem da peça suscita um racha, fruto de uma divergência teórica de seus participantes. Segundo Paulo Hime, ele, juntamente com Vianinha, Chico de Assis, Leon Hirszman, e outros militantes e simpatizantes do Partido Comunista Brasileiro (PCB) se distanciam do Grupo Jovem, isto é, de seu diretor, Kleber Santos, e dos atores Joel Ghivelder, seu irmão Moisés Ghivelder, e outros artistas (VIANNA FILHO, 2016, p. 114). Depois de expressada a divergência política, aqueles interessados em dar continuidade ao trabalho de A mais-valia se articulam para promover outras atividades, em parceria com a UNE. É a partir da aglomeração de artistas e intelectuais, identificados com um projeto de cultura popular, que nasce o CPC da UNE. 
O CPC não realiza atividades apenas no Rio de Janeiro, mas é levada a outros estados, sobretudo a partir do projeto chamado UNE-Volante, que ocorre de agosto de 1961 a julho de 1962 sob a gestão de Aldo Arantes, membro da Ação Popular (AP), eleito presidente da entidade estudantil em 1961.

Em Santo André, o CPC surge em setembro de 1961, a partir da realização de um festival, em que são apresentadas as peças: Os fuzis da senhora Carrar, de Bertolt Brecht, no Sindicato dos Metalúrgicos, encenada pelo Teatro da Praça, seguida pela apresentação de A semente, de Gianfrancesco Guarnieri, realizada pelo Teatro Brasileiro de Comédia, e a peça O Testamento do cangaceiro, de Chico de Assis, pelo Teatro de Arena. O festival conta também com a apresentação do mímico Ricardo Bandeira e da bailarina Marilena Ansaldi (SILVA, 2000, p. 252).

Desde sua criação, o CPC de Santo André recebe grandes influências da produção do CPC da Guanabara, assim como dos integrantes do Teatro de Arena, responsáveis por orientar e dirigir grande parte de suas montagens. Isso ocorre com as peças O Formiguinha1', escrita por Arnaldo Jabor, e Eles não usam black tie, de Guarnieri, sob a direção de Chico de Assis. Esta última estreia em 1962 no Sindicato dos Metalúrgicos de Santo André (Id., 1991, p. 34).

O que é possível saber sobre a montagem da primeira peça é que ela contou no seu elenco com Angelo Del Mato e Sonia Guedes - atriz que também participa da montagem de Eles não usam black tie - interpretando a personagem Maria, junto a Guedes de Souza como Tião, Nina Neri como Romana, e outro atores como Miguel Benvenga e Orlando Gazetti (Ibid., p. 40).

A montagem dessas peças também acaba por influenciar a produção teatral local, permitindo a criação de dramaturgias como O berço de Suzana, escrita por Jurandir Alécio e dirigida por Augusto Boal, e Heróis de barro e A lombriga, ambas escritas pelos próprios operários metalúrgicos da região (CAMACHO, 1999, p. 119).

Até o momento, as peças não foram encontradas, mas sabemos do que trata a dramaturgia de $O$ berço de Suzana, a partir do relato do próprio autor:

1. Sobre a montagem de O Formiguinha, ela provavelmente ocorreu em 1962, no Sindicato dos Metalúrgicos de Santo André (Ibid., 1991, p. 40). 
Zola, o personagem central, depois de vinte e um anos de casado, tem uma filha: Suzana. Compra para Suzana o que tem de melhor. Berço e enxoval caríssimos, de modo que faz dívidas pesadas e fica com medo de perder o emprego. Daí não participa de nenhum movimento de seus companheiros. Não acompanha o avanço da tecnologia, não se atualiza, deixa de interessar à firma e é dispensado. Aquele que atua desperta a solidariedade dos companheiros, é defendido pelo Sindicato, sendo, portanto, um pouco mais difícil de manda-lo embora. O Berço de Suzana era mais ou menos isso. (lbid., p. 129)

O CPC de Santo André, diferente dos CPC de outras cidades, fica conhecido como o CPC de base operária. Em uma reportagem no jornal Diário do Grande $A B C$, aparece a informação de que "havia, em média, de 20 a 30 participantes ativos do CPC, a maioria operários"2 (MEDICI, 1987, p. 24). Tratava-se, portanto, ainda que em partes, de um rompimento com que havia sido o Teatro de Arena, constituído de integrantes e de um público de estudantes e intelectuais de classe média.

Segundo Vianinha, um dos principais impulsionadores do CPC da UNE, - Teatro de Arena havia se tornado limitado com relação ao seu alcance, apesar de seu conteúdo a favor do proletário. Para o dramaturgo, apesar de denunciar as chamadas "problemáticas do capital", o Arena não denunciava os seus próprios "vícios capitalistas", culminando em um "teatro inconformado" e não em um "teatro de ação":

O Arena contentou-se com a produção de cultura popular, não colocou diante de si a responsabilidade de divulgação e massificação. Isto sem dúvida repercutiria em seu repertório, fazendo surgir um teatro que denuncia os vícios do capitalismo, mas que não denuncia o capitalismo ele mesmo. O Arena, sem contato com as camadas revolucionárias de nossa sociedade, não chegou a armar um teatro de ação, armou um teatro inconformado. Guarnieri, Boal podem ou não escrever peças de ação, mas um movimento de cultura popular não pode depender de talentos pessoais- é preciso que a empresa tenha uma existência objetiva de tal tipo que a obrigue a mobilizar todos os seus elementos na criação de um tipo de teatro. Uma empresa que

2. Trata-se de uma reportagem sobre a pesquisa de Thimoteo Camacho sobre o CPC de Santo André, que só iria ser publicado em forma de livro em 1999. O depoimento é de José Vieira de Oliveira. Cf. Medici (Op. cit., p. 24). 


\section{O Centro Popular de Cultura de SantoAndré e sua proposta de um teatro proletário}

seja sustentada pelo povo para, objetivamente, ser obrigada a falar e ser entendida por esse povo. (PEIXOTO, 1999, p. 93)

A partir, portanto, da análise que o Arena era um teatro limitado por não entrar em contato com "as camadas revolucionárias da nossa sociedade", o autor conclui que é preciso construir um teatro de "massa":

Um movimento de cultura popular usa o artista corrente, usa uma ideologia de espetáculo que precisa pertencer à empresa, e não aos seus representantes individuais. Nenhum movimento de cultura pode ser feito com um autor, um ator, etc. É preciso massa, multidão. Ele não pode depender e viver atrás de obras excepcionais- o movimento é que é excepcional na medida em que supera as condições objetivas que monopolizam a formação cultural das massas. (Ibid., p. 93)

A análise de Vianinha se assemelha a conclusão de Jurandir Alécio, um dos impulsionadores do teatro do CPC em Santo André e vereador pelo Partido Trabalhista Brasileiro (PTB) entre 1960 a 1963, que defendia uma arte sem privilégios, feita para as "massas". Nos anais da câmara municipal, conforme citado por Vieitez (1999, p. 68), aparece o discurso de Alécio, que faz uma fala em defesa da produção artística do CPC:

A arte no Brasil está enfeixada, praticamente, nas mãos de uma meia dúzia de privilegiados e, o que é pior, está subordinada aos interesses dessa meia dúzia. O Centro Popular de Cultura há de levar o teatro, a música, o cinema às grandes massas do povo [...]. (Ibid., p. 68)

Se por um lado o CPC de Santo André recebe influências do Teatro de Arena, sobretudo na construção dramatúrgica e na direção das peças; por outro, por estar intimamente ligado ao movimento operário, sua prática artística ganha um novo sentido, levando a discussão trazida na cena à realidade mais próxima do cotidiano tanto do público como de seus próprios integrantes.

Por ser uma novidade no campo artístico para Santo André, o CPC acaba atraindo também atores pertencentes ao Sociedade de Cultura Artística de Santo André (Scasa), participantes de grupos amadores da cidade, vinculados a associações, fábricas e clubes, além de artistas plásticos, músicos e críticos de cinema. 
O Scasa nasce em 1953, na Escola Júlio de Mesquita, com a peça Ingênua até certo ponto, com a companhia de Nicete Bruno. Seus primeiros diretores foram: Antonio Pezzolo, Sebastião de Oliveira Campos, José Miranda, René Zmekhol, Mario Brazão, Reinaldo Custódio dos Santos, Guido Carali, Alcides Montagner e Antonio Chiarelli (ASSUMPÇÃO, 2000, p. 18).

Depois de ser impossibilitado de se apresentar na sede da Escola Mesquita Filho, o Scasa se articula para ter um novo espaço. Em 1962 é criado o Teatro de Alumínio em Santo André, na rua Coronel Alfredo Flaquer, com 300 lugares, que é "instalado no terreno que é de propriedade do sr. José Calis Daher - antigo morador de Santo André,' o qual, segundo Chiarelli, em entrevista realizada para a matéria do jornal O Repórter, intitulada Um teatro de alumínio para Santo André: um empreendimento da Sociedade de Cultura Artística- Capacidade para 300 lugares, havia "favorecido bastante a Sociedade a ponto de não cobrar o aluguel" (Ibid., p. 38). Tratava-se de um empreendimento do Scasa, que contava com a ajuda de autoridades municipais e de apoio empresarial para ser construído.

Segundo Chiarelli, em uma entrevista realizada para o jornal News Seller do ABC paulista, de 25 de junho de 1961, além da inauguração, era "desejo da Diretoria para SA o TBC, o Teatro de Arena, Nídia Lícia e seu elenco, o quarteto de cordas de Santos e muitos outros." (AMORIM, 1961, p. 4). E depois, em uma outra reportagem deste mesmo jornal, em 10 de dezembro de 1961, é destaque a estrutura teatral construída com pouco recurso, determinada inclusive pela produção industrial local:

Para a construção do teatro, como já foi dito, foi utilizado de tudo... desde que não custasse dinheiro. O piso, por exemplo, foi feito com madeira de embalagens de automóveis e geladeiras. [...] As paredes são de zinco e, em algumas folhas, pode-se ver o céu do outro lado. (QUASE..., 1961, p. 5)

Apesar do Scasa manter relações com profissionais de outras cidades, sua produção nos anos de 1960 ainda se vinculava, segundo José Armando Pereira da Silva, a "um tipo de encenação que havia sido ultrapassada pelo moderno teatro brasileiro" (SILVA, 2000, p. 250-251), havendo poucos indícios 
sobre "uma preocupação com um grande potencial de público em expansão, que era a classe operária e o estudante" (Ibid., p. 251).

É durante o período de existência do CPC que o teatro em Santo André passa por um processo de profissionalização. Esse processo fica mais evidente a partir de 1963, quando o Governo do Estado promove, por meio do Conselho Estadual de Cultura e a Comissão Estadual de Teatro, o I Festival de Teatro Amador do Estado de São Paulo, que ocorre no Teatro de Alumínio (Ibid., p. 253).

Nesse período, há um acirramento da competição entre grupos amadores, que passam a ser julgados por comissões, disputando a premiação que é dada em forma de bolsa de estudo para a Escola de Arte Dramática (EAD). É a partir desse processo que o Scasa substitui as comédias de costume por dramaturgias do repertório do Teatro de Arena e de autores como Bertolt Brecht e Tenessee Williams, o que possibilita, de certa forma, criar as condições necessárias para o surgimento, em 1968, do Grupo de Teatro da Cidade (GTC), considerado o primeiro grupo profissional de Santo André, impulsionado sobretudo pelas ideias e iniciativas de Heleny Guariba.

O CPC de Santo André não exerce apenas influências na área teatral, mas em diversas áreas artísticas, já que também havia sido responsável por impulsionar atividades para as crianças, de criar um coral - com treinamento vocal, em que os participantes cantavam, dentre outras músicas, o hino do CPC - um curso de cinema, de admissão ao ginásio e também de filosofia. Este último tinha o objetivo de formar militantes que, segundo Alaor Caffé candidato a vereador em Santo André na época de funcionamento do CPC - "poderiam ser futuramente recrutados pelo Partido Comunista." Tratava-se de aulas de "filosofia marxista, economia política, história do movimento operário e realidade brasileira, da perspectiva nacionalista" (CAMACHO, Op. cit., p. 132).

No caso de Santo André, o CPC encontra suas bases vinculadas ao Sindicato dos Metalúrgicos e não tanto à entidade estudantil, como no Rio de Janeiro, em que o CPC era vinculado a UNE. O que não necessariamente significou o afastamento de sua produção da juventude; pelo contrário, em Santo André, os jovens representavam grande parcela daqueles que impulsionavam suas atividades artísticas. 
Sobre isso, é importante ressaltar que as concepções culturais e artísticas dos jovens integrantes do CPC nem sempre eram as mesmas das dos quadros do Partido Comunista que, na época, era predominante no Sindicato dos Metalúrgicos em Santo André, cuja direção era composta, entre 1958 a 1964, por Marcos Andreotti, membro do PCB, que também havia sido um dos fundadores e presidente desse sindicato, em 1934.

José Armando Pereira da Silva, um dos coordenadores do curso de cinema do CPC de Santo André afirma, em entrevista realizada para este trabalho, em 2018, que alguns dirigentes do PCB enxergavam na produção a artística uma "coisa meio de elite", "fora do repertório do que eles esperavam,' e que mostravam preferência para "bailes, carnaval, etc".

Também Rolando Frati, secretário geral do Partido Comunista desse período, afirma que alguns militantes viam o CPC como "coisa de molecada", e que havia, segundo ele, "uma objeção de ordem moral", um medo que atividades que incluíssem homens e mulheres juntos instaurassem a "promiscuidade" no Sindicato (VIEITEZ, Op. cit., p. 70).

Segundo Cândido Vieitez, em Reforma Nacional-Democrática e ContraReforma: a política do PCB no Coração do ABC Paulista, 1956-1964, o PCB não controlava e dirigia as atividades do $\mathrm{CPC}$, porém havia um interesse do Partido em relação a aproximação da "camada média" da sociedade, pequenos proprietário e profissionais liberais por meio das atividades artísticas, o que incluía a renovação dos quadros do Partido - sobretudo aqueles que careciam de formação - e também a agregação de jovens que chegavam muitas vezes a militar por intermédio da Associação de Universitários de Santo André (Ausa), que inicialmente servia para organizar festas, bailes e eventos sociais de entretenimento para a juventude (Ibid., p. 73).

A ideia de aproximação do Partido Comunista com as "camadas médias" da sociedade está associada a sua política de converter o Partido em um instrumento poderoso do ponto de vista "numérico e organizativo", voltado a "intensificação do trabalho ideológico" (VINHAS, 1982, p. 183-184), o que teve reflexos na construção do próprio CPC, responsável por atrair artistas e intelectuais. 
As ideias vinculadas a construção do Partido estão presentes também na chamada Declaração de Março (1958), que forneceu a base teórica à Resolução do V Congresso de 1960, e que defendeu a política de frente única, traduzida na aliança entre o proletariado e a burguesia nacional:

O proletariado e a burguesia se aliam em torno do objetivo comum de lutar por um desenvolvimento independente e progressista contra o imperialismo norte-americano [...] Embora explorado pela burguesia, é do interesse do proletário aliar-se a ela, uma vez que sofre mais do atraso do país e da exploração imperialista do que do desenvolvimento capitalista. (DECLARAÇÃO SOBRE A POLÍTICA DO PCB, 1980 apud SEGATTO, 1981, p. 81)

A Resolução do V Congresso caracteriza, nos anos de 1960, a Revolução brasileira como "anti-imperialista e antifeudal, nacional e democrática" (SEGATTO, Op. cit., p. 86) o que se configura muito mais em uma ideia "etapista" - e, portanto, idealista, de "transformação social" dentro dos limites capitalistas, por meio de uma aliança com setores da burguesia nacional - do que em uma política revolucionária:

A contradição antagônica entre o proletariado e a burguesia, inerente ao capitalismo, é também uma contradição fundamental da sociedade brasileira. Mas esta contradição não exige solução radical e completa na atual etapa da Revolução, uma vez que, na presente situação do País, não há condições para transformações socialistas imediatas. [...] Em sua atual etapa, a revolução brasileira é anti-imperialista e antifeudal, nacional e democrática. (RESOLUÇÃO POLÍTICA DO V CONGRESSO DO PCB, DECLARAÇÃO SOBRE A POLÍTICA DO PCB, 1980 apud Ibid., p. 86)

Parte considerável da produção textual sobre a história do Partido considera a Resolução do V Congresso um rompimento com o dogmatismo e o sectarismo, associando-a, de forma equivocada, à teoria marxista. Este é o caso de Edgard Carone, que enxerga na Resolução um combate a limitações do próprio Partido, e não um entrave à luta política do proletariado:

O mérito principal da linha geral aprovada no $V$ Congresso consiste em que supera ambas as limitações- a dogmatização dos princípios e o oportunismo afastado dos princípios-, as quais, na sua dialética de opostos, alimentam-se 
mutuamente. E, por isso mesmo, a linha geral do V Congresso permite combater estas limitações, não a partir de uma contra a outra, mas contrapondo-se simultaneamente a uma e outra, a partir de uma posição marxista correta. (CARONE, 1982, p. 230)

Ou então, Moisés Vinhas, que considera a conciliação de classe expressa na política de frente única do Partido uma questão menor, na medida em que interpreta que o Partido possa apoiar reformas dentro da estrutura do "atual regime", sem que isso necessite levar a um rompimento com o atual sistema, ou à uma chamada "solução radical":

Quanto à contradição antagônica entre burguesia e proletariado, a "Resolução" de 1960 considera que não há no país condições para transformações socialistas imediatas, e que ela não exige solução radical na "atual etapa histórica". Por outro lado, reconhece ser viável a obtenção de um conjunto de reformas econômicas e políticas ainda "nos quadros do atual regime." (VINHAS, Op. cit., p. 183)

A luta "anti-imperialista e antifeudal, nacional e democrática" (Ibid.) não se expressa apenas na luta do Partido, mas também no próprio CPC, presente na escolha de seu repertório e na temática de suas peças. Ainda que a documentação sobre o CPC de Santo André seja escassa - praticamente toda perdida com o Golpe de 1964 - a relação do teatro com a fábrica e o operariado, e as contribuições e contradições dessa prática ainda aparecem como uma oportunidade para pensar o papel da produção teatral vinculada à luta política.

\section{Referências bibliográficas}

AMORIM, Marina. SCASA constrói teatro de 300 lugares em SA. News Seller. Santo André, p. 4, 25 jul. 1961.

ASSUMPÇÃO, Paschoalino. $O$ teatro amador de Santo André: a sociedade de cultura artística (SCASA) e o Teatro de Alumínio. Santo André: Alpharrabio Edições, 2000.

$\mathrm{CAMACHO}$, Thimoteo. Cultura dos trabalhadores e crise política: estudos sobre o Centro Popular de Cultura do Sindicato dos Metalúrgicos de Santo André. Santo André: Fundo de Cultura do Município de Santo André; Secretaria de Cultura, Esporte e Lazer, 1999.

CARONE, Edgard. Corpo e alma do Brasil: o PCB (1943-1964). São Paulo: Difel, 1982. 
COSTA, Iná Camargo. A hora do teatro épico no Brasil. Rio de Janeiro: Paz e Terra, 1996.

MAYOR et al. Nota Introdutória. In: VIANNA FILHO, Oduvaldo. Peças do CPC: A mais-valia vai acabar, seu Edgar e Mundo enterrado. São Paulo: Expressão Popular, 2016.

$\mathrm{MEDICI}$, Ademir. Santo André busca suas raízes, do CPC à igreja. Diário do Grande ABC, Santo André, 22 nov. 1987. Caderno D, p. 24.

PEIXOTO, Fernando. (org.). Vianinha: teatro, televisão, política. São Paulo: Brasiliense, 1999.

QUASE terminado o teatro do scasa: inauguração em janeiro. News Seller. Santo André, p. 5, 10 dez. 1961.

SEGATTO, José Antonio. Breve história do PCB. São Paulo: Livraria Editora Ciências Humanas, 1981.

SILVA, José Armando Pereira da. O teatro em Santo André. Santo André: Public Gráfica e Fotolito Ltda, 1991.

SILVA, José Armando Pereira da. Província e vanguarda: apontamentos e memória de influências culturais, 1954-1964. Santo André: Fundo de Cultura do Município de Santo André; Secretaria de Cultura, Esporte e Lazer, 2000.

VIANNA FILHO, Oduvaldo. Peças do CPC: a mais-valia vai acabar seu Edgar e mundo enterrado. São Paulo: Expressão Popular, 2016.

VIEITEZ, Candido Giraldez. Reforma Nacional-Democrática e Contra-Reforma: a política do PCB no Coração do ABC Paulista, 1956-1964. Santo André: Fundo de Cultura do Município de Santo André, Secretaria de Cultura, Esporte e Lazer, 1999.

VINHAS, Moisés. O Partidão: a luta por um partido de massas (1922-1974). São Paulo: Hucitec, 1982.

Recebido em 14/09/2018

Aprovado em 14/11/2018

Publicado em 06/05/2019 